\title{
Small-molecule compounds targeting the STAT3 DNA-binding domain suppress survival of cisplatin-resistant human ovarian cancer cells by inducing apoptosis
}

Wei Huang ${ }^{\mathrm{a}, \mathrm{b}, \dagger}$, Yuan Liu ${ }^{\mathrm{b}, \dagger}$, Jun Wang ${ }^{\mathrm{a}}$, Xia Yuan ${ }^{\mathrm{b}}$, Hong-Wei Jin ${ }^{\mathrm{b}}$, Liang-Ren Zhang ${ }^{\mathrm{b}}$, JianTing Zhang ${ }^{\mathrm{c}}$, Zhen-Ming Liu ${ }^{\mathrm{b}, *}$ and Jing-Rong Cui ${ }^{\mathrm{a}}$

a Department of Pharmacology, Institute of Basic Medical Sciences, Chinese Academy of Medical Sciences and School of Basic Medicine, Peking Union Medical College, Beijing, 100005, P.R. China

${ }^{b}$ State Key Laboratory of Natural and Biomimetic Drugs, School of Pharmaceutical Sciences, Peking University, Beijing, 100191, P.R. China

${ }^{c}$ Department of Pharmacology and Toxicology and IU Simon Cancer Center, Indiana University School of Medicine, Indianapolis, Indiana, 46202, United States

${ }^{\dagger}$ Equal contributors

* Corresponding author: Zheng-Ming Liu, State Key Laboratory of Natural and Biomimetic Drugs, School of Pharmaceutical Sciences, Peking University, Beijing, 100191, P.R. China. Email address: zmliu@bjmu.edu.cn. 


\begin{abstract}
Constitutive activation of signal transducer and activator of transcription 3 (STAT3) plays important roles in oncogenic occurrence and transformation by regulating the expression of diverse downstream target genes important for tumor growth, metastasis, angiogenesis and immune evasion. Feasibility of targeting the DNA-binding domain (DBD) of STAT3 has been proven previously. With the aid of 3D shape- and electrostatic-based drug design, we identified a new STAT3 inhibitor, LC28, and its five analogs, based on the pharmacophore of a known STAT3 DBD inhibitor. Microscale thermophoresis assay shows that these compounds inhibits STAT3 binding to DNA with a Ki value of $0.74 \sim 8.87 \mu \mathrm{M}$. Furthermore, LC28 and its analogs suppress survival of cisplatin-resistant ovarian cancer cells by inhibiting STAT3 signaling and inducing apoptosis. Therefore, these compounds may serve as candidate compounds for further modification and development as anticancer therapeutics targeting the DBD of human STAT3 for treatment of cisplatin-resistant ovarian cancer.
\end{abstract}

Keywords: signal transducer and activator of transcription 3 (STAT3); DNA binding domain (DBD); similarity screening; microscale thermophoresis; cisplatin resistance

\title{
Highlights
}

- DNA-binging domain of STAT3 may not be 'undruggable' as previously thought

- LC28 and five analogs were identified through the pharmacophore of known STAT3 inhibitors with 3D shape- and electrostatic-based drug design

- Microscale thermophoresis assay shows that these compounds inhibits STAT3 binding to DNA with a Ki value of $0.74 \sim 8.87 \mu \mathrm{M}$.

- LC28 and its analogs suppress survival of cisplatin-resistant ovarian cancer cells by 
inhibiting STAT3 signaling and inducing apoptosis. 


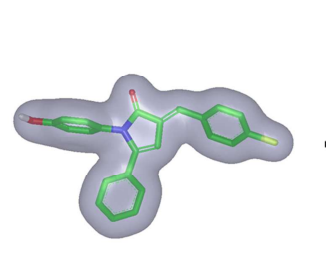

Query model
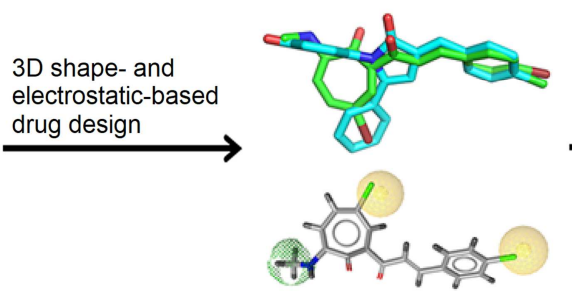

LC28 and its analogs

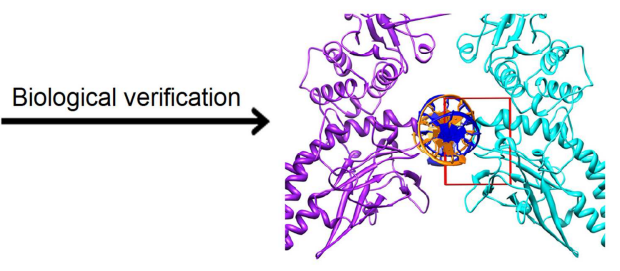

Targeting DBD of STAT3 


\section{Introduction}

Signal transducer and activator of transcription 3 (STAT3) is a transcription factor of STAT family [1]. In response to various extracellular cytokines and growth factors, STAT3 is activated and phosphorylated at tyrosine residue 705 (Tyr705) by cell surface-associated receptor tyrosine kinases followed by dimerization, nuclear translocation, binding to specific elements in genomic DNA and activation of target gene transcription [2-6]. In normal cells, activation of STAT3 signaling is transient and strictly controlled. However, aberrant STAT3 signaling induces cell proliferation and prevent apoptosis in cancer cells by upregulating its downstream genes such as bcl-2, cyclin D1, survivin, twist, MMPs and VEGF [7-18]. Numerous clinical studies have shown that up-regulation of phosphorylated STAT3 (pSTAT3) is correlated to poor prognosis in patients with ovarian, colorectal, gastric, pancreatic, renal and cervical cancers [19-25]. In a study conducted in 341 patients with ovarian cancer, positive expression of p-STAT3 was observed in $28 \%$ of patients and was identified as an independent worse prognostic factor for overall survival [26]. Additionally, constitutively activated STAT3 contributes to insensitivity to various therapeutics via aberrant production of cytokines or growth factors in cancer cells [27, 28]. STAT3 signaling also interplays with a variety of signaling pathways to maintain tumor malignancy including Ras/MAPK, mTOR/PI3K/Akt, NF-kB and Wnt pathways [29-31]. As a result, aberrant transcription of anti-apoptotic genes such as survivin suppresses programed cell death induced by cytotoxic agents $[13,32]$. The STAT3 pathway responds early to platinum drugs in cisplatin-resistant ovarian cancer cells. Exposure of ovarian cancer cells to interleukin-6 (IL-6) to activate STAT3 signaling results in the expression of anti-apoptotic proteins [33]. Moreover, cisplatin-induced chemokine ligand 5 (CCL5), a secreted protein derived from cancer-associated fibroblasts, attenuates the cytotoxic effect of cisplatin chemotherapy in ovarian 
cancer cells by promoting STAT3 and PI3K/Akt signaling pathways [34]. Higher expression of CCL5 is also observed in chemotherapy-resistant patients than in chemosensitive patients [35]. Treatment with STAT3 inhibitor enhances the chemosensitivity of cisplatin-resistant ovarian cancer cells, indicating that STAT3 serves as an attracting therapeutic target of ovarian cancer $[36,37]$.

In fact, a large number of STAT3 inhibitors have reflected a significant research area, including but not limited to inhibiting STAT3 activation, disrupting STAT3 dimerization or blocking STAT3-DNA binding [38-40]. Targeting upstream kinases for STAT3 activation such as JAK inhibitors (AG490, WP1066, TG101209 and AZD1480) may be limited to inhibit STAT3 signaling as diverse factors are involved in activation of STAT3 [41-45]. A variety of inhibitors targeting STAT3 protein directly have been designed and identified using peptidomimetics, structure-based virtual screening, fragment-based drug design or highthroughput screening. Most of these STAT3 inhibitors mimick binding to the SH2 domain of STAT3, which favors receptor recognition for activation and dimerization of STAT3 by reciprocal binding to Try705. These inhibitors include but are not limited to small peptides (PpYLKTK and pYLPQTV), peptide mimetic (ISS610) and small molecule inhibitors (S3IM2001, STA-21, S3I-201 and Stattic) [46-52]. However, STAT3 may involve in oncogenesis and transcriptional regulation in the absence of tyrosine phosphorylation. Unphosphorylated STAT3 has been shown to sustain cytokine-dependent signaling in complex with NF-kB [53]. Thus, targeting SH2 domain and inhibiting STAT3 phosphorylation and dimerization may be insufficient to suppress aberrant STAT3 signaling. In addition, the STAT3 SH2 domain is a highly conserved region with a high sequence similarity to other proteins such as phospholipase 
C- $\gamma$, Src, phosphatidylinositol 3-kinase and other STATs $[54,55]$. Such structural similarity is also challenging to develop specific STAT3 inhibitors.

The physical interaction between STAT3 and the promote region of its downstream genes is essential for the transcriptional activity of STAT3, and DNA-binding domain (DBD) of STAT3 is thus a potential drug target. A phase 0 clinical trial conducted for STAT3 decoy oligodeoxynucleotides that blocks DNA binding of STAT3 has demonstrated the feasibility of targeting the DBD of STAT3 in humans [56]. Despite DBDs have been considered "undruggable" because active DNA-binding sites are too shallow or too similar to permit tight and specific binding of small molecules to DBD, Zhang et al identified a small molecule inhibitor, inS3-54, that binds directly to the DBD of STAT3, using an improved in-silico approach [57]. Molecular simulation analysis showed that the compound binds to the residues Met331, Val343, Met420, Ile467 and Met470 in the DBD of STAT3 via hydrophobic interaction with the aid of Lys340 and Asn466 to stabilize the carboxyl group of inS3-54 by favorable electrostatic interaction [57]. Further structure and activity-guided hit optimization study let to identification of a series of inS3-54 analogs including inS3-54A18 (A18) with enhanced specificity and pharmacological properties [58].

Ligand-based virtual screening is a viable computational technique that is widely used in early-stage drug discovery $[59,60]$. It requires only a little amount of bioactive molecule structures to produce structurally novel compounds through skeletal transition. With the aid of this approach, we identified LC28 and five analogs through the pharmacophore of A18 with 3D shape- and electrostatic-based drug design. These compounds suppressed survival of cisplatinresistant ovarian cancer cells by interrupting STAT3-DNA interaction and by inhibiting the expression of STAT3 downstream target genes. Collectively, we conclude that STAT3 inhibitors 
targeting its DBD may be developed as alternative therapeutics treating drug-resistant ovarian cancers.

\section{Results}

\subsection{Ligand-based virtual screening of small-molecule compounds targeting the DBD of STAT3}

To identify STAT3 inhibitors with improved potency and specificity, the ligand-based pharmacophore models of STAT3 inhibitors were generated by using LigandScout 3.12 in combination with 3D shape- and electrostatic-based drug design approach followed by searching the Specs chemical library (Fig.1). The pharmacophore models were created with the existing STAT3 inhibitors including inS3-54, A18, A26 and A69 (Fig.2A). All compounds share similar backbone, 5-phenyl-1H-pyrrol-2(3H)-ketone. Based on previous structure-activity relationship analysis, the compounds with $\mathrm{R}_{1}$ group being hydrogen bond donor appear to be active for STAT3 inhibition, such as $p$-hydroxyphenyl or $p$-carboxyphenyl, while hydrophobic centroids such as $p$-nitrophenyl or $p$-chlorophenyl as the $\mathrm{R}_{2}$ group are favorable [57]. Hence, in the three pharmacophore models we constructed, the hydrogen bond donor at position $\mathrm{R}_{1}$ and the hydrophobic group at position $\mathrm{R}_{2}$ were considered the common pharmacophore characters among the Pharma 1, Pharma 2 and Pharma 3 (Fig.2B-C). Meanwhile, the hydrophobic interaction between the 5-benzene ring and the hydrogen bond acceptor of the 2-carbonyl group was reflected in the Pharma 1, Pharma 2 and Pharma 3, respectively. To identify novel skeletal structure, no pharmacophore character was given for the backbone structure.

Searching the Specs chemical library with Pharma 1, Pharma 2 and Pharma 3 resulted in 218,497, 39,114 and 25,169 molecules, respectively. The next 3D shape- and electrostatic-based similarity search used an optimized conformation of A18 as ROCS query to search new 
compound database using the ROCS 3.1.2. As a result, the top 5,000 compounds were retained based on 'TanimotoShape' score (a shape similarity parameter) in each structure. EON 2.1.0 was then employed to calculate the Electrostatic Tanimoto of the retained compounds according to the original query, and the top 500 compounds were retained based on the 'ET_pb' score (an electrostatic similarity parameter) in each structure. Eventually, 1,500 compounds were recruited, clustered and visually examined, and 5, 18 and 21 compounds were selected from the retained compounds of Pharma 1, Pharma 2 and Pharma 3, respectively (Supplemental Tab.S2). Four of these 44 compounds have duplicated structures and were eliminated from further testing.

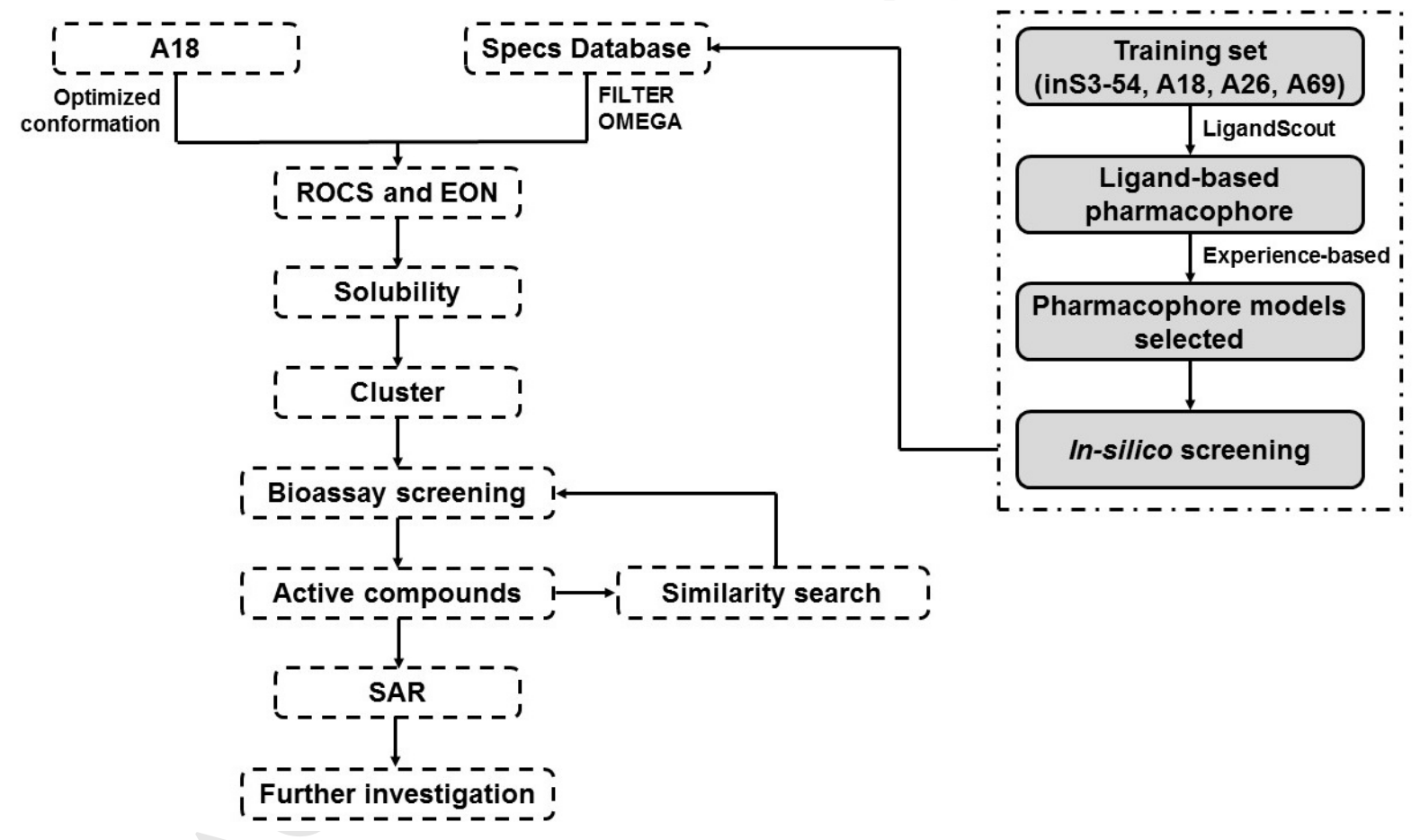

Fig.1 Summary for workflow of Ligand-based virtual screening and bioassay. 
A
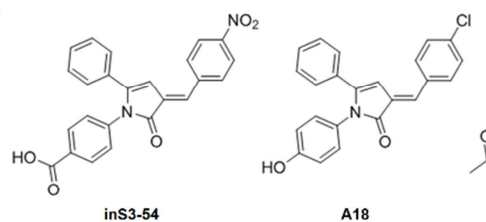

A18

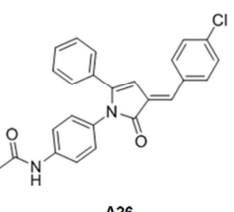

A26

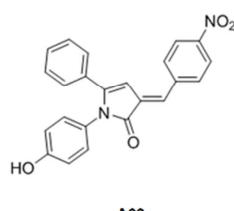

A69
B

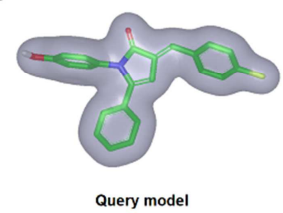

Query model

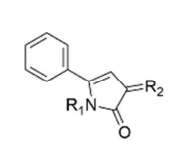

Core structure of ins $3-54$
and its analogs

D
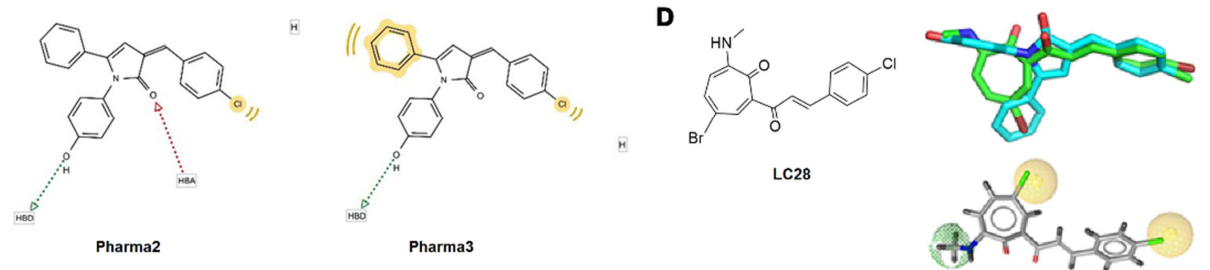

E

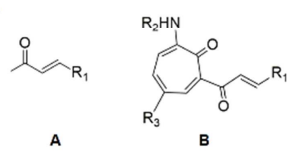

Core structure of LC28

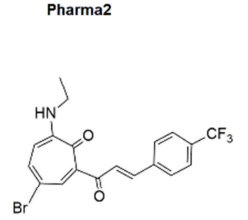

LC28-11

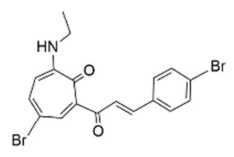

LC28-17

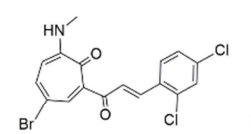

LC28-24

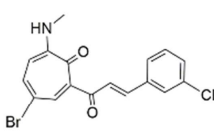

LC28-28

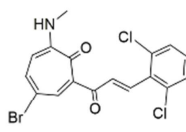

LC28-29

Fig.2 Construction of three pharmacophore models and identification of LC28 and its analogs by ligandbased virtual screening. (A) Chemical structures of known STAT3 inhibitors developed by Zhang et al. and their core structure. (B) Query model used for 3D similarity search. (C) Three pharmacophore models we constructed using training set molecules. (D) Chemical structures of LC28 and overlay of LC28 structure with A18 or Pharma3. (E) Core structures and chemical structures of LC28 and its analogs.

\subsection{Identification of a small-molecule compound targeting the DBD of STAT3}

To determine the activity of these 40 compounds, we designed a two-step biological screening assay including cytotoxicity assay and microscale thermophoresis [43] analysis. As STAT3 inhibitors are known to inhibit cancer cell proliferation, the first cell viability assay was used to shorten the list for MST screening. One of the 40 compounds, LC28 from Pharm 3, exhibited inhibitory activity on survival of $\mathrm{H} 1299$ cells with an $\mathrm{IC}_{50}$ of $8.1 \pm 4.1 \mu \mathrm{M}$ (Fig.3A-B) while the $\mathrm{IC}_{50}$ of the known STAT3 inhibitor A26 accounted for $3.4 \pm 0.2 \mu \mathrm{M}$ [58]. To determine the effect of LC28 on the DNA-binding activity of STAT3, we developed a competitive experiment using MST technique, which characterizes ligand-binder interaction based on the directed movement of molecules along temperature gradients. By using fluorescent Cy5-labeled probe and total lysates of H1299 cells transiently transfected with constitute active STAT3c expression construct, we determined the specific binding of the Cy5-labeled probe to STAT3 in 
total lysates of H1299 cells overexpressing STAT3c with a $K_{d}$ of $85.07 \mathrm{ng} / \mu$ l compared to total lysates of cells without STAT3c construct ( $\left.K_{d}: 516.71 \mathrm{ng} / \mu \mathrm{l}\right)$ (Fig.3C-D). To validate the specific binding between Cy5-labeled probe and STAT3, the cell lysate was pretreated with unlabeled probe or a known STAT3 inhibitor, inS3-54A26 (A26), followed by incubation with Cy5-labeled probe. The $K_{i}$ values of unlabeled probe and A26 were determined to be $2.82 \mathrm{nM}$ and $2.50 \mu \mathrm{M}$, indicating the feasibility of this procedure in testing the candidate compounds for competitive inhibition of STAT3 binding to Cy5-labeled probe (Fig.3E-F). As shown in Fig.3G, the $K_{i}$ of LC28 was estimated to be $3.92 \mu \mathrm{M}$, suggesting that LC28 inhibits the DNA-binding activity of STAT3 (Fig.3G). Despite distinct difference in 2D structure, LC28 matched well with A18 in 3D structure with similar pharmacophore characteristics (Fig.2D). ShapeTanimoto accounted for 0.711 and ET_pb was 0.348 . Collectively, LC28 represents a novel compound targeting the DBD of STAT3. 
A

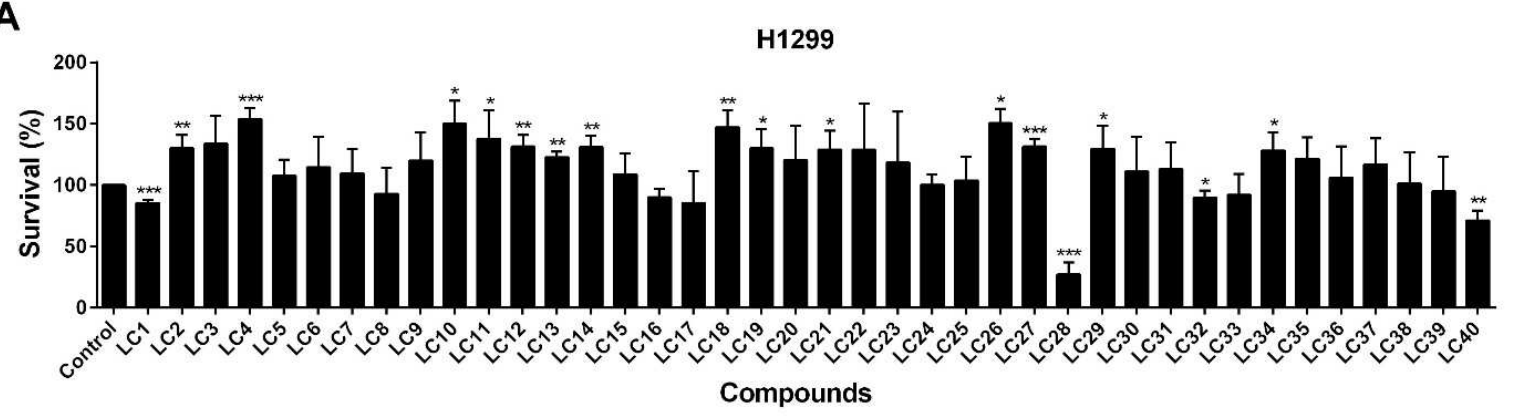

B

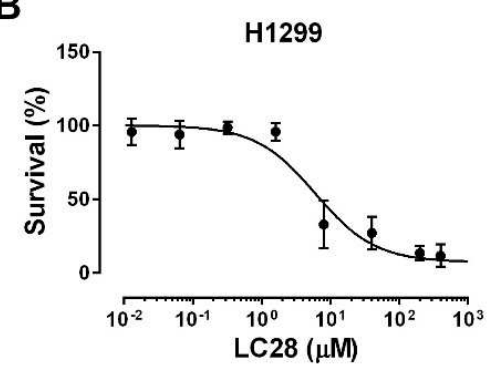

E

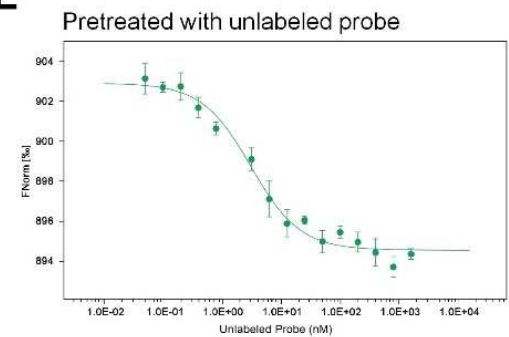

C

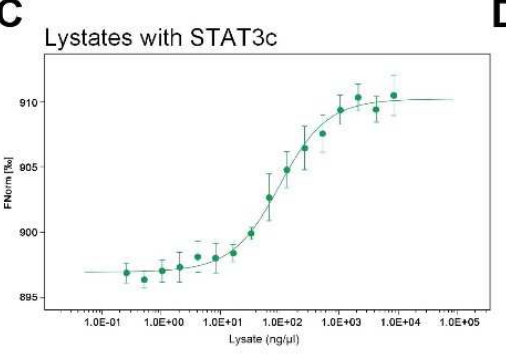

D

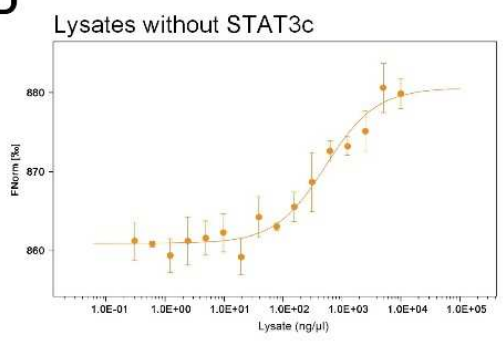

$\mathbf{F}$

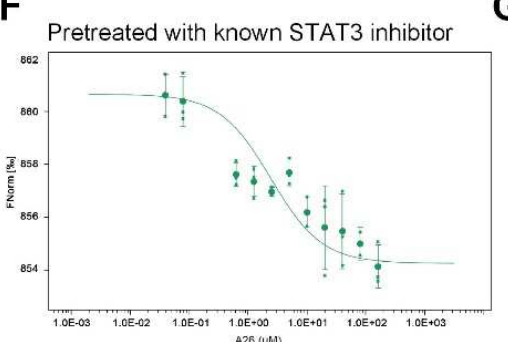

G

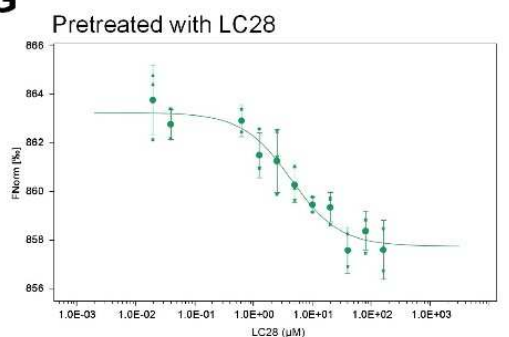

Fig.3 Identification of LC28 targeting the DBD of STAT3. (A) Cytotoxicity assay of 40 compounds obtained from ligand-based virtual screening. H1299 cells were exposed to $5 \mu \mathrm{M}$ of indicated compounds for $72 \mathrm{~h}$ followed by SRB assay. (B) Cell survival curve of LC28 in H1299 cells. H1299 cells were treated with increasing concentrations of LC28 for $72 \mathrm{~h}$ followed by SRB assay. Dose-response curves were computed by using GraphPad Prism software. (C-G) MST binding curves to Cy5-labeled DNA probe, C: cell lysates with STAT3c, D: cell lysates without STAT3c, E: cell lysates pretreated with unlabeled probe, F: cell lysates pretreated with a known STAT3 inhibitor, inS3-54A26, G: cell lysates pretreated with LC28. (* $p<0.05, * * p<0.01, * * * p<0.001$, by Student's $t$-test as compared with vehicle control) 


\subsection{Identification of active analogs of LC28 targeting the DBD of STAT3}

To optimize LC28, we searched the Specs chemical library for its analogs using molecular fingerprint ECFP_6 in the PipelinePilot 7.5. By designating two core structures, A and B, 31 analogs were tested for their activity in suppressing cell survival and STAT3 DNA binding activity (Fig.2E; Supplemental Tab.S3). With the same biological screening procedure, 31 analogs were first tested using cytotoxicity assay in H1299 cells. As shown in Fig.4A, LC28-1, $7,-9,-11,-12,-16,-17,-19,-21,-22,-23,-24,-27,-28$ and -29 suppressed survival of H1299 cells with an inhibition rate of more than $70 \%$. These compounds were then tested in MST assay as well, and 5 of which inhibits the binding of STAT3 to Cy5-labeled probe (Fig.4C-G). The $K_{i}$ values of LC28-11, $-17,-24,-28$ and -29 were $8.87,1.01,1.40,1.18$ and $0.74 \mu \mathrm{M}$, respectively. Compared to the known STAT3 inhibitor inS3-54A26 $\left(K_{i}: 2.50 \mu \mathrm{M}\right)$ and the parental compound LC-28 $\left(K_{i}: 3.92 \mu \mathrm{M}\right)$, LC28-17, -24, -28 and -29 appeared more effective to inhibit STAT3 DNA binding activity. Further cytotoxicity assay demonstrated their $\mathrm{IC}_{50}$ in $\mathrm{H} 1299$ cells were 3.3 5.8 $\mu \mathrm{M}$, suggesting their potential as novel anti-cancer drugs (Fig.4B). All of 5 active compounds belong to the core structure B, which is more refined to develop LC28 analogs. 
A

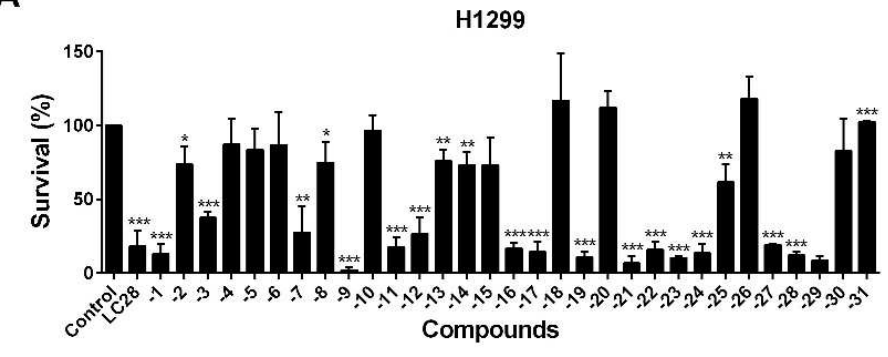

C

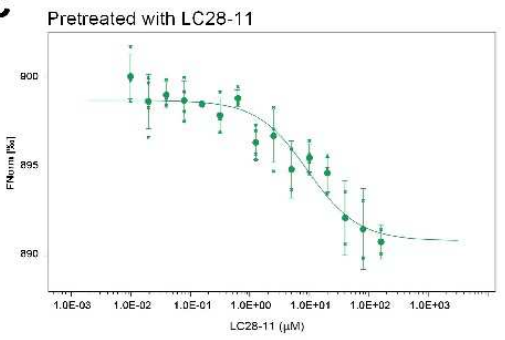

$\mathbf{F}$

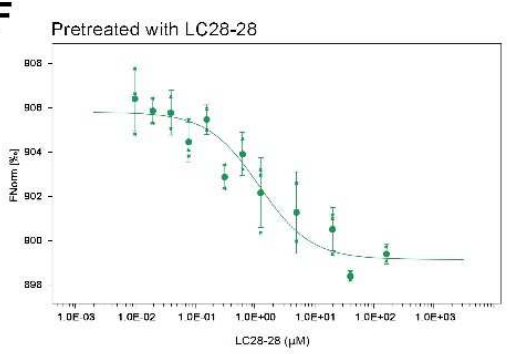

B

D Pretreated with LC28-17

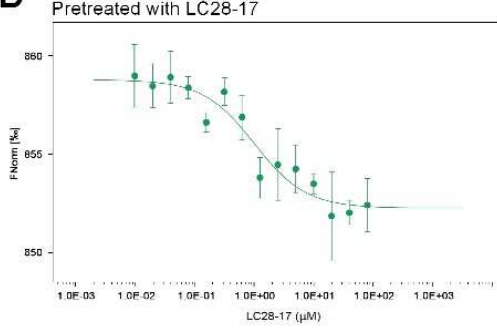

G

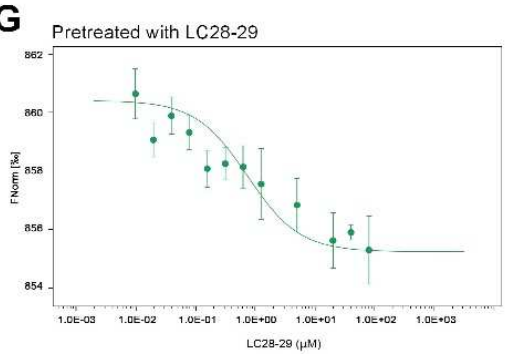

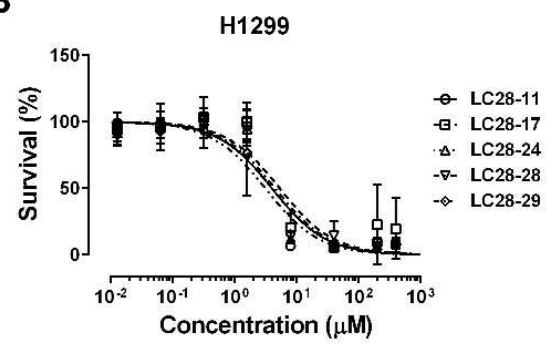

E Pretreated with LC28-24

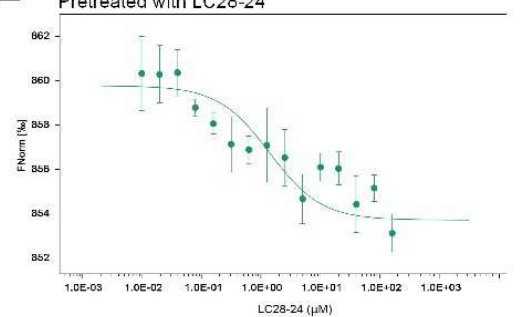

Fig.4 Identification of active LC28 analogs targeting the DBD of STAT3. (A) Cytotoxicity assay of 31 LC28 analogs obtained from ligand-based virtual screening. H1299 cells were exposed to $5 \mu \mathrm{M}$ of indicated compounds for $72 \mathrm{~h}$ followed by SRB assay. (B) Cell survival curve of five LC28 analogs in H1299 cells. H1299 cells were treated with increasing concentrations of LC28 for $72 \mathrm{~h}$ followed by SRB assay. Dose-response curves were computed by using GraphPad Prism software. (C-G) MST binding curves to Cy5-labeled DNA probe, C: cell lysates pretreated with LC28-11, D: cell lysates pretreated with LC28-17, E: cell lysates pretreated with LC28-24, F: cell lysates pretreated with LC28-28, G: cell lysates pretreated with LC28-29. (* $p<0.05$, ** $p<0.01$, *** $p<0.001$, by Student's $t$-test as compared with vehicle control) 


\subsection{LC28 and its active analogs suppress survival of cisplatin-resistant ovarian cancer cells}

It has been known that persistent STAT3 signaling is associated with cisplatin resistance in epithelial ovarian cancer $[37,61]$. To investigate the potential use of LC28 and its active analogs for treating cisplatin resistant ovarian cancer, we examined the effectiveness of these compounds on survival of SKOV3 and its cisplatin-resistant counterpart SKOV3/DDP cells. The five analogs showed comparable inhibitory activity with LC28 in SKOV3 cells while their $\mathrm{IC}_{50}$ appear to be lower than LC28 in SKOV3/DDP cells (Fig.5; Tab.1). These data suggest the use of novel STAT3 inhibitor to treat cisplatin resistance.

A

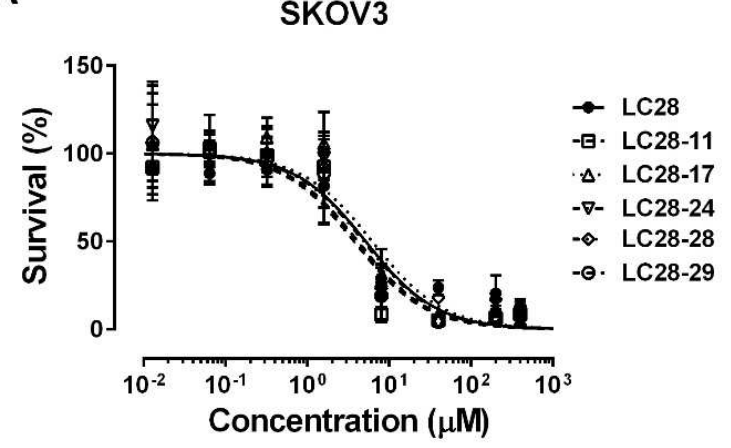

B

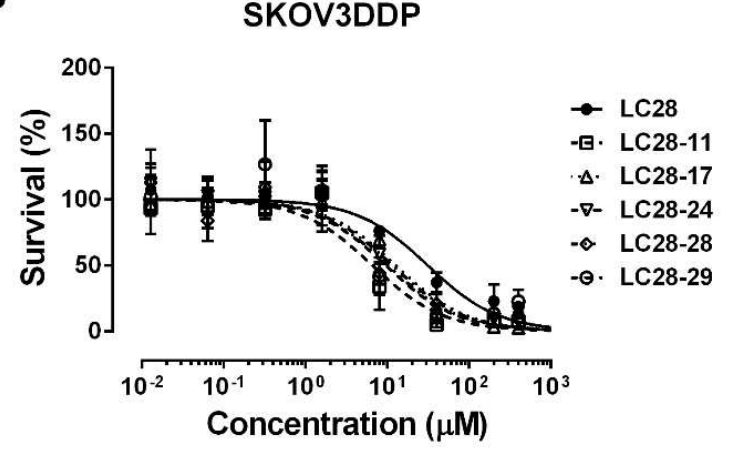

Fig.5 LC28 and its analogs inhibits survival of cisplatin-sensitive and -resistant ovarian cancer cells. (A) SKOV3 and (B) SKOV3/DDP cells were exposed to increasing concentrations of LC28 or its analogues for $72 \mathrm{~h}$ followed by SRB assay. Dose-response curves were computed by using GraphPad Prism software.

Tab.1 $\mathrm{IC}_{50}$ of LC28 and its analogs $(\mu \mathrm{M})$

\begin{tabular}{lccc}
\hline \multicolumn{1}{c}{ Cell line } & H1299 & SKOV3 & SKOV3/DDP \\
\hline Histology & Non-small cell lung cancer & Ovarian cancer & Cisplatin-resistant ovarian cancer \\
\hline LC28 & $8.1 \pm 4.1$ & $3.7 \pm 0.7$ & $14.7 \pm 2.4$ \\
LC28-11 & $3.8 \pm 0.5$ & $3.8 \pm 1.0$ & $7.2 \pm 1.7$ \\
LC28-17 & $5.3 \pm 0.1$ & $5.6 \pm 0.7$ & $9.4 \pm 6.2$ \\
LC28-24 & $4.1 \pm 0.6$ & $4.5 \pm 1.3$ & $9.8 \pm 3.9$ \\
LC28-28 & $4.3 \pm 1.1$ & $3.5 \pm 1.3$ & $7.4 \pm 0.1$ \\
LC28-29 & $3.3 \pm 1.7$ & $3.6 \pm 1.2$ & $7.0 \pm 2.2$ \\
\hline
\end{tabular}




\subsection{LC28 and its active analogs inhibits expression of STAT3 downstream target genes}

It has been shown that constitutive STAT3 signaling promotes chemoresistance via upregulation of anti-apoptotic factors such as survivin $[13,32]$. To validate the effect of LC28 and its active analogs on STAT3 signaling in cells and elucidate the mechanism whereby the compounds inhibit survival of cisplatin-resistant SKOV3/DDP cells, we determine the expression of factors involving in STAT3 pathway by Western blotting and qPCR analyses. Although the expression of cyclin D1 and survivin are both decreased in dose- and timedependent manners when SKOV3/DDP cells were exposed to LC28, the phosphorylation of STAT3 at Tyr705 was reduced with little effect on total STAT3 level (Fig.6A and Fig.S1A-B). The qPCR analysis of mRNAs also confirmed this observation (Fig.6B). Furthermore, the active LC28 analogs all down-regulated the expression of cyclin D1 without any effect on pSTAT3 and STAT3 (Fig.6C-D and Fig.S1C). Interestingly, the phosphorylation of STAT3 at Tyr705 was also decreased after LC28 treatment with little effect on total STAT3 level (Fig.6A). To further tested whether LC28 affects cytokine-induced STAT3 activation, serum-starved SKOV3/DDP cells were treated with control vehicle or $15 \mu \mathrm{M}$ LC28 and then subjected to IL-6 stimulation and Western blotting analysis of pSTAT3 (Tyr705). As shown in Fig.6E and Fig.S1D, LC28 decreased the pSTAT3 level, suggesting that LC28 pretreatment impaired IL-6-induced STAT3 phosphorylation. 
A

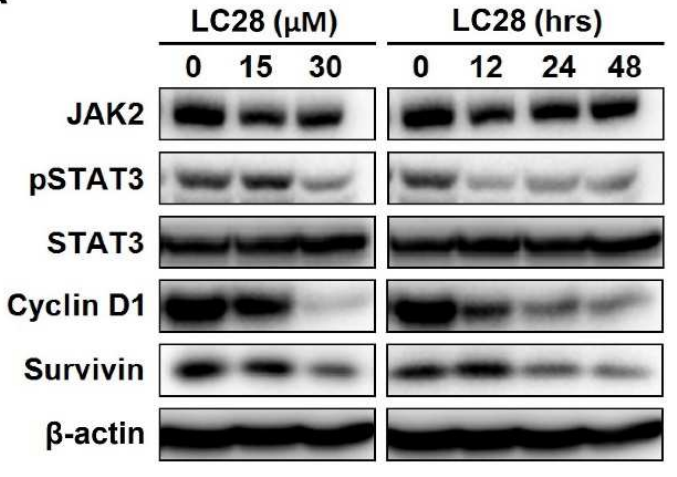

B

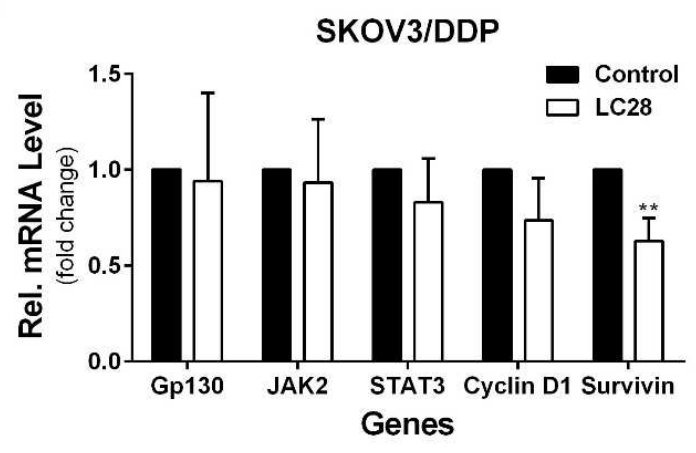

C

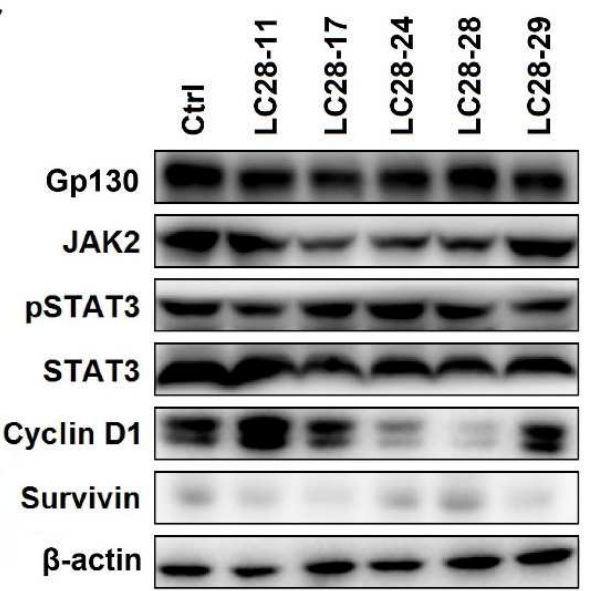

D

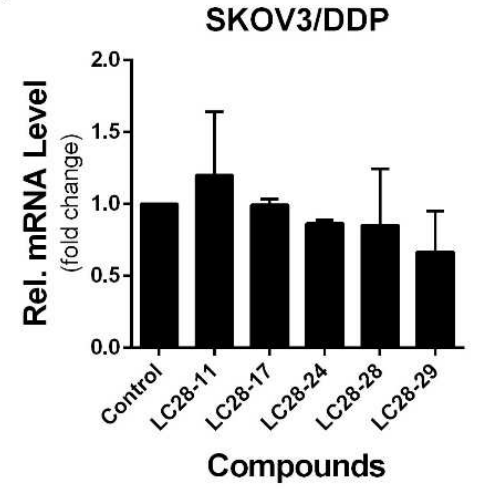

E

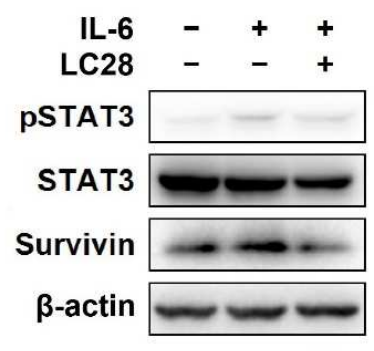

Fig.6 LC28 and its analogs inhibits STAT3 signaling pathway. (A) Effect of LC28 on the protein expression of STAT3 signaling pathway in SKOV3/DDP cells after treatment with LC28. SKOV3/DDP cells were exposed to DMSO $(0.1 \%), 15$ or $30 \mu \mathrm{M}$ of LC28 for $48 \mathrm{~h}$ or $15 \mu \mathrm{M}$ of LC28 for $0,12,24$ and $48 \mathrm{~h}$ followed by lysate preparation and Western blot analyses with antibodies indicated. $\beta$-actin was used as a loading control. (B) Effect of LC28 on the mRNA expression of STAT3 signaling pathway in SKOV3/DDP cells after treatment with LC28. SKOV3/DDP cells were exposed to DMSO $(0.1 \%), 15$ or $30 \mu \mathrm{M}$ of LC28 for $48 \mathrm{~h}$ or $15 \mu \mathrm{M}$ of LC28 for $0,12,24$ and $48 \mathrm{~h}$ followed by total RNA extraction and real-time qPCR analysis. Data show the relative mRNA levels normalized to the internal control, GAPDH. (C-D) Effect of LC28 analogs on the protein (C) and mRNA (D) expression of STAT3 signaling pathway in SKOV3/DDP cells. SKOV3/DDP cells were exposed to DMSO (0.1\%) or $10 \mu \mathrm{M}$ of LC28-11, -17, -24, -28 and -29 for $48 \mathrm{~h}$ followed by Western blot or qPCR analyses of STAT3 signaling pathway. (E) SKOV3/DDP cells were pretreated with $15 \mu \mathrm{M} \mathrm{LC} 28$ for $48 \mathrm{~h}$ followed by IL-6 $(100 \mathrm{ng} / \mathrm{ml})$ stimulation and subjected to Western blotting analysis of pSTAT3 (Y705), STAT3, survivin and $\beta$-actin. 


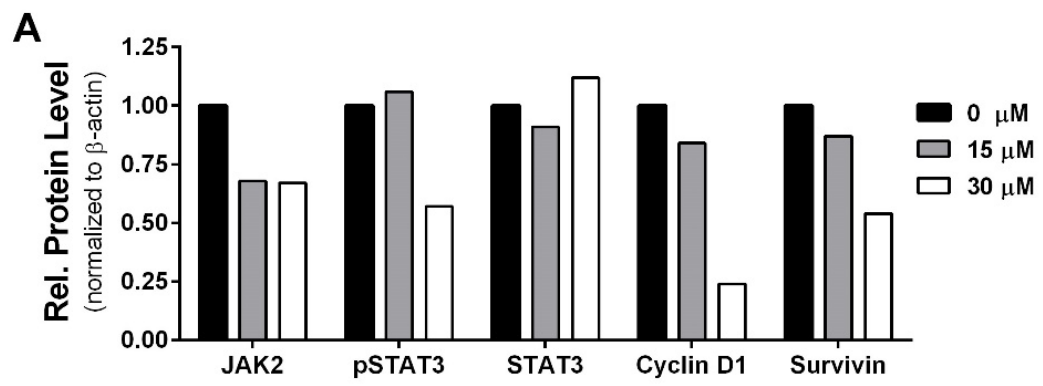

B

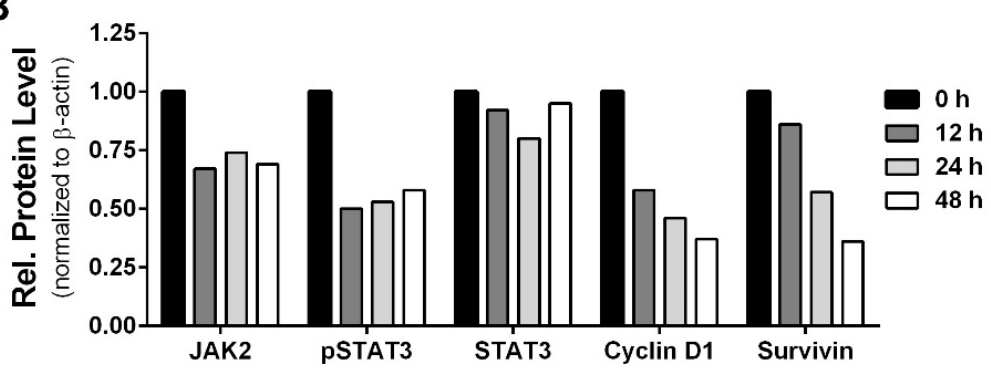

C

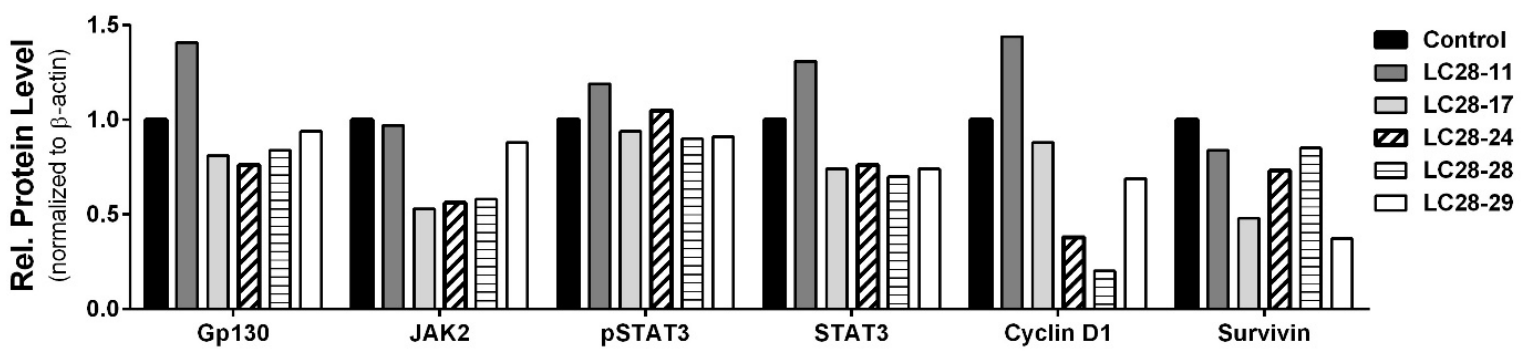

D

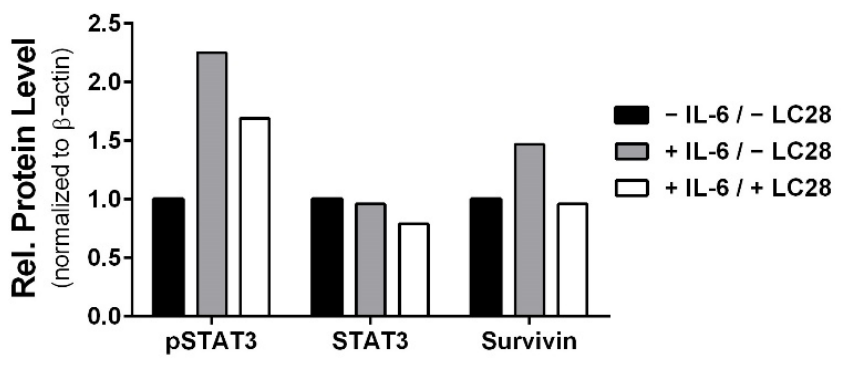

Fig.S1 Quantitative data of Western blot bands in Fig.6. Relative protein level was measured by the density of Western blot bands and normalized against the $\beta$-actin internal control. (A-B) Fig.6A. (C) Fig.6C. (D) Fig.6E. 


\subsection{LC28 and its active analogs induce apoptosis of SKOV3/DDP cells}

To determine if apoptosis contributes to the suppression of SKOV3/DDP cell survival following treatment with LC28 or its active analogs, flow cytometry assay was performed to quantify apoptotic cells. As evident from Fig.7, the percentages of early and late apoptotic cells increased to $16 \%$ and $22 \%$ upon treatment of SKOV3/DDP cells with 15 and $30 \mu \mathrm{M}$ LC2 8 for 48 $\mathrm{h}$, respectively, as compared to untreated cells. The apoptotic cells accounted for $21 \%, 14 \%$, $12 \%, 95 \%$ and $88 \%$ following exposure to $10 \mu \mathrm{M} \mathrm{LC} 28$ analogs for $48 \mathrm{~h}$. These findings suggest that LC28 and its analogs may be effective in inducing apoptosis and suppressing survival of cisplatin-resistant ovarian cancer cells. These compounds deserve further investigations for development of novel STAT3 inhibitors. 
A

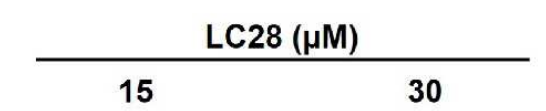

\section{Control}

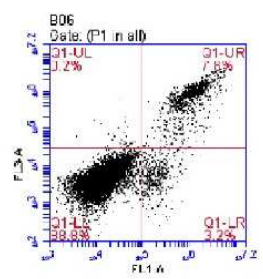

LC28-11

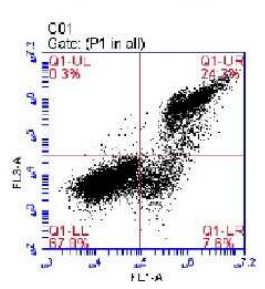

B
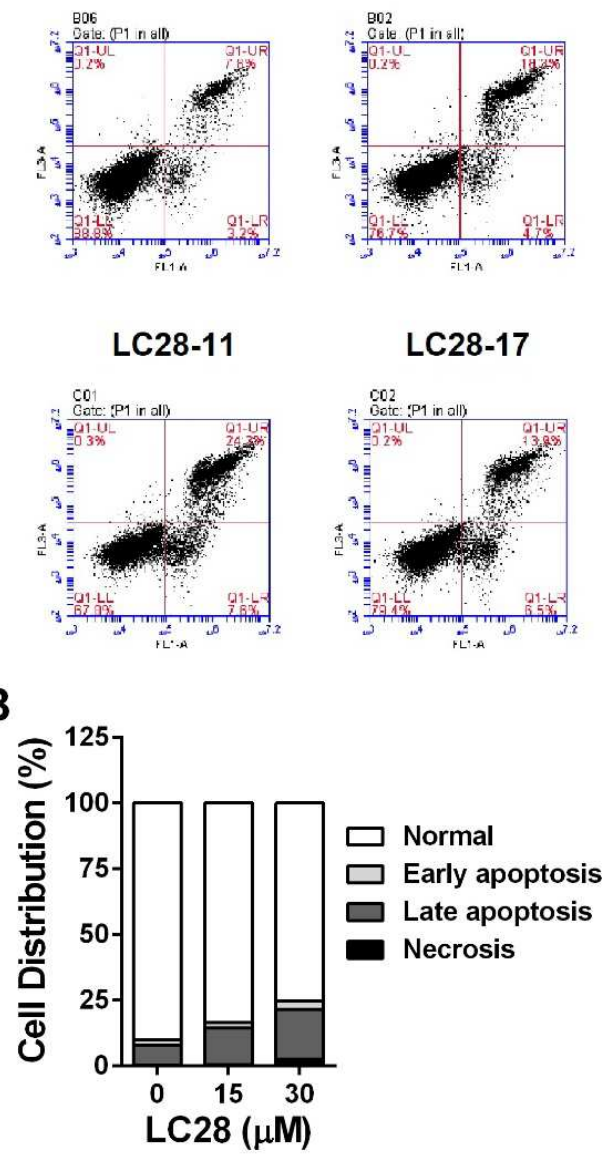

LC28-17

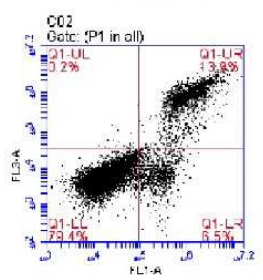

30

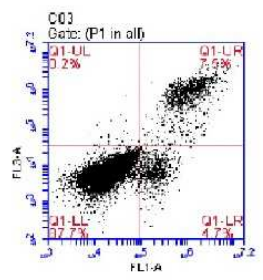

LC28-28

LC28-29
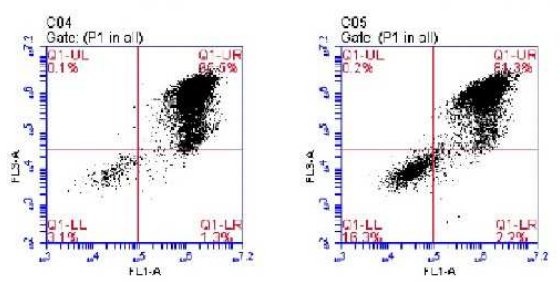

\section{C}

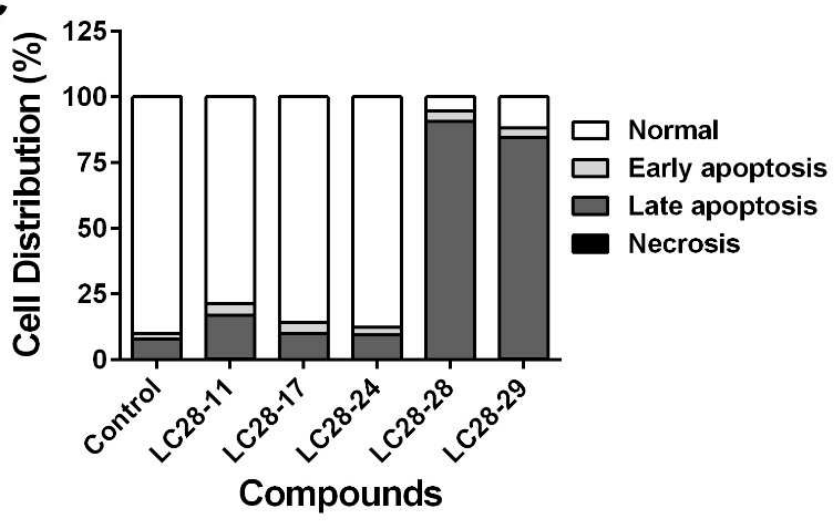

Fig.7 LC28 and its analogs induce apoptosis in SKOV3/DDP cells. (A) Following exposure to vehicle control, 15 or $30 \mu \mathrm{M} \mathrm{LC} 28$, or $10 \mu \mathrm{M}$ each of LC28 analogs for $48 \mathrm{~h}$, apoptotic SKOV3/DDP cells were stained with Annexin V and PI followed by flow cytometry analysis. Shown is a representative of flow cytometry data, including viable cells (left bottom quadrant), early apoptotic cells (right bottom quadrant), late apoptotic cells (right upper quadrant) and necrotic cells (left upper quadrant). (B-C) Percentages of cells in each quadrant are shown. 


\section{Discussion}

In previous studies, inS3-54 and its analogs were found to target the DNA-binding domain of STAT3, leading to suppression of tumor growth, metastasis and STAT3 target gene expression $[57,58]$. Considering that targeting STAT3 DBD is more effective to eliminate aberrant STAT3 signaling in cancer cells, we expect to identify novel STAT3 inhibitors for development of anticancer therapeutics. This study successfully identified LC28 and its analogs targeting the DBD of STAT3. These compounds disrupt the binding of STAT3 to DNA and thus inhibit STAT3 downstream gene expression. As a result, down-regulation of cyclin D1 and survivin contributes to suppression of cisplatin-resistant SKOV3/DDP cell survival by inducing apoptosis. These characteristics make them potential lead compounds for further modification and development.

Interestingly, LC28 inhibits the binding of STAT3 to Cy5-labeled DNA probe whereas constitutive and IL-6-induced STAT3 phosphorylation is abrogated by LC28 treatment. Despite the potential of off-target effect, we speculate that the binding LC28 to STAT3 DBD may impair its phosphorylation through conformational blockage. Nevertheless, how LC28 interacts with specific residues in the DBD of STAT3 awaits further investigation. To identify potent STAT3 inhibitors, we screened 31 analogs of LC28 by developing a new and efficient microscale thermophoresis-based approach, which can quantify the ability of a compound to inhibit STAT3 DNA-binding activity in 10 minutes. Of 31 LC28 analogs, five active compounds share a core structure with a bromo-substituent at $\mathrm{R}_{3}$ as shown in Fig.2E. The existence of $p$-bromophenyl (LC28-17) groups at $\mathrm{R}_{1}$ facilitates their activity in inhibiting STAT3 DNA binding with $\mathrm{R}_{2}$ being ethyl group whereas LC28-11 containing $p$-trifluoromethylphenyl at $\mathrm{R}_{1}$ displayed lower DNAbinding inhibition than the parental compound, LC28, as evidenced by MST assay. When $\mathrm{R}_{2}$ is 
methyl group, compounds with $\mathrm{R}_{1}$ being $m$-chlorophenyl (LC28-24), 1,3-dichlorophenyl (LC2828) or 1,5-dichlorophenyl (LC28-29) groups favor STAT3 inhibition. However, whether the combination of $\mathrm{R}_{1}$ and $\mathrm{R}_{2}$ groups affects the binding affinity to STAT3 remains unclear. More structure-activity relationship studies would be helpful to determine the effect of side groups on the STAT3 inhibitory activity of compounds. It is noteworthy that LC28 analogs showed relatively lower $\mathrm{IC}_{50}$ values than LC28 in cisplatin-resistant SKOV3/DDP cells. Meanwhile, LC28-28 and -29 were more effective in inducing apoptosis than the parental compound. Despite no one-by-one correspondence between MST assay and cell viability and cell apoptosis assays, it remains unclear whether the potent effect is resulted from STAT3 inhibition via different side groups of LC28 and its analogs and the potential off-target effects cannot be ruled out. Thus, the favorable effect in inducing apoptosis awaits further verification in vivo and more in-depth mechanism studies.

Platinum-based chemotherapy including cisplatin or carboplatin represents a standard treatment for treatment of ovarian cancer for decades. As one of the most effective broadspectrum anticancer drugs, cisplatin forms DNA-platinum adducts after entering cells while affecting multiple genes and resulting in dramatic cellular alternations [62]. A considerable percentage of primary cancers are at least partially resistant to cisplatin. As a result, cancer patients have to be exposed to potential side effects of chemotherapy. Generally, cisplatin insensitivity is a consequence of numerous epigenetic and genetic changes including reduction in the intracellular platinum accumulation, increased DNA damage repair, inactivation of apoptosis and alternation in DNA methylation, microRNA profile and stress-response chaperones [63, 64]. It is therefore exceedingly important to identify alternative therapeutics for patients who are resistant to chemotherapy. A variety of compounds targeting drug transporter, apoptosis-related factors and cell growth-promoting genes can resensitize cisplatin-resistant ovarian cancer cells to 
cisplatin [65-67]. Interfering with cellular accumulation of cisplatin and platinum-induced cell death enables direct pharmacological intervention and offers therapeutic options on a patient-bypatient basis. Constitutive activation of STAT3 is common in a variety of tumor cell types. This aberrant STAT3 signaling implicates STAT3 as not only an oncogene but also an anti-apoptotic factor in the resistance to cell-mediated cytotoxicity and chemotherapeutic drug treatment. The fact that $\mathrm{IC}_{50}$ of $\mathrm{LC} 28$ is higher in SKOV3/DDP cells than in the parental cells suggests that STAT3 may contribute to cisplatin resistance. We also found a higher pSTAT3 level in SKOV3/DDP cells than in SKOV3 cells (data not shown). Our observation that LC28 and its analogs suppress survival of SKOV3/DDP cells by inhibiting STAT3 signaling may promise these compounds as potential alternative therapeutics for treatment of cisplatin-resistant cancers. In addition, STAT3-targeted therapies prove to be a potential strategy for chemosensitization of cancerous cells. For example, cucurbitacin B, a STAT3 signaling inhibitor, enhances cisplatin sensitivity in laryngeal squamous cell carcinoma cells [68]. Of course, further research on combination treatment of LC28 or its analogs with chemotherapeutic agents might strengthen the significance of our study.

Collectively, LC28 or its analogs may serve as candidates for further development as anticancer therapeutics targeting the DBD of human STAT3 for treatment of cisplatin-resistant ovarian cancer and DBD of transcription factors may not be 'undruggable' as previously thought.

\section{Experimental Section}

\subsection{Chemicals and reagents}

All candidate compounds were purchased from the Specs chemical library (Zoetermeer, Netherlands), dissolved in dimethyl sulfoxide (DMSO) to a concentration of $20 \mathrm{mM}$ and 
preserved at $-20^{\circ}$ C. Antibodies against), cyclin D1 (Cat. No. 2798), JAK2 (Cat. No. 3230), pSTAT3 (Cat. No. 9145), STAT3 (Cat. No. 9139), survivin (Cat. No. 2808) and $\beta$-actin (Cat. No. 4970) were obtained from Cell Signaling Technology (Danvers, MA, USA). Antibodies against GAPDH (Cat. No. sc-25778) and glycoprotein 130 (gp130; Cat. No. sc-656) were purchased from Santa Cruz Biotechnologies (Santa Cruz, CA, USA).

\subsection{Virtual screening}

\subsubsection{Preparation of compound library}

The Specs chemical library (http://www.specs.net/) was used for in-silico screening. In brief, the database was prepared by using a homemade protocol in Pipeline Pilot v7.5 (PP 7.5, Accelrys, San Diego, CA, USA), in which the molecules formed 3D coordinates to remove counter ions, minimize and standardize. Then, the prepared database was filtered by a basic standard in FILTER to eliminate molecules with unsatisfied properties. The FILTER criteria we used was the default BlockBuster filter in OpenEye software (OEChem version 1.9.1; OpenEye Scientific, OpenEye Scientific, Santa Fe, NM, USA), which includes a large number of physical property limits such as minimum and maximum molecular weight, minimum and maximum number of heavy atoms, and minimum solubility (see filter_blockbuster.txt of OpenEye software for details). Subsequently, the database was prepared with OMEGA, an efficient tool for reproducing bioactive conformations, to generate up to 500 conformations for each molecule.

\subsubsection{Ligand-based pharmacophore screening}

Generation of ligand-based pharmacophore. The first step is to generate a ligand-based pharmacophore model according to the known STAT3 inhibitors, inS3-54 and its active analogs 
(A18, A26 and A69). Their 3D structures were generated and minimized using 'Prepare Ligand' module in Discovery Studio 2.5 (Accelrys) and imported into LigandScout 3.12 (Inte:Ligand, Maria Enzersdorf, Austria) for automated generation of pharmacophore models by 'Create Ligand-Based Pharmacophore' module. To obtain precise pharmacophore models for STAT3 inhibitors targeting DBD, structure-activity relationship of inS3-54 and its analogs was taken into consideration to modify the automated pharmacophore models. Eventually, three pharmacophore models (Pharma1, Pharma2 and Pharma3) were generated and used for screening of the Specs chemical library by using LigandScout 3.12 with default parameters. All the compounds that match the three pharmacophore models were included in a new compound dataset for the next step of virtual screening by using 'ROCS' and 'EON' modules in OpenEye software.

Shape-based virtual screening. For shape-based 3D similarity search, the optimized conformation of A18 was used to generate ROCS query by using ROCS 3.1.2 (OpenEye Scientific Software). The 3D conformation of A18 was generated and minimized using 'Prepare Ligand' module in Discovery Studio 2.5 followed by searching the database obtained from pharmacophore screening with the query model. The results were ranked by 'TanimotoShape' score and the top 5,000 compounds were retained for each pharmacophore model.

Electrostatic-based virtual screening. ROCS output compounds (oeb.gz) were used as input for electrostatic-based analysis by using EON 2.1.0 (OpenEye Scientific Software), which calculates the Electrostatic Tanimoto between each molecule and the query rather than performing overlay or changing the input orientation of the structures. New partial charges for the input structures were computed using MMFF94. The output files were then ranked by the 'ET_pb' score, and the top 500 compounds were retained for each pharmacophore model. 
$2 D$ similarity search. The promising hits were subjected to $2 \mathrm{D}$ similarity search to find more compounds with same or similar scaffold. Molecular fingerprint ECFP_6 in Pipeline Pilot v7.5 was used to search the Specs chemical library. To explore the structure-activity relationship of these compounds, compounds with similar structure skeletons were selected by the Tanimoto coefficient (Tc) for activity evaluation.

\subsubsection{Water solubility prediction and structure cluster analysis}

The selected compounds were processed for ADMET solubility prediction by using Pipeline Pilot v7.5. Briefly, the water solubility was computed at $25^{\circ} \mathrm{C}$ and designated as 0 (extremely low), 1 (very low), 2 [69], 3 (good), 4 (optimal) or 5 (very soluble). The molecules with ADMET solubility level at 0 or 1 were ruled out to ensure that the chosen compounds have acceptable solubility. Then cluster analysis was performed in Pipeline Pilot v7.5 by ECFP6 to choose the compounds for bioassays.

\subsection{Cell culture}

Human ovarian cancer cells (SKOV3), cisplatin-resistant human ovarian cancer cells (SKOV3/DDP) and human non-small cell lung cancer cells (H1299) were cultured in RPMI 1640 medium (Macgene, Beijing, China), supplemented with $10 \%$ fetal bovine serum (PANBiotech $\mathrm{GmbH}$, Aidenbach, Germany) and $1 \%$ penicillin/streptomycin (Macgene) in a $37^{\circ} \mathrm{C}$ humidified atmosphere containing $5 \% \mathrm{CO}_{2}$.

\subsection{Cell viability assay}


To shorten the list for microscale thermophoresis screening of STAT3 inhibitors targeting its DBD, sulforhodamine B (SRB) assay was first used to determine the cytotoxicity of candidate compounds obtained from virtual screening. In brief, 3000 cells/well H1299 cells were seeded in a 96-well plate. $24 \mathrm{~h}$ later, the cells were exposed to $5 \mu \mathrm{M}$ of each compound for $72 \mathrm{~h}$ as we previously described $[70,71]$. Then, the culture medium was discarded and the cells were fixed and stained in $0.4 \%$ (w/v) SRB staining solution followed by incubation at room temperature for 20 min. Unbound SRB dyes were removed by washing four times with $1 \%$ acetic acid. 200 $\mu \mathrm{L} /$ well of $10 \mathrm{mM}$ unbuffered Tris base was added to solubilize the bound SRB after air-drying overnight at room temperature. Optical density (OD) was determined at $570 \mathrm{~nm}$ using Infinite ${ }^{\circledR}$ F50 absorbance plate reader (Tecan, Switzerland). Cell viability was determined and calculated using the following formula as compared with vehicle control $(0.1 \%$ DMSO): Survival $(\%)=$ $\mathrm{OD}_{\text {Treatment }} / \mathrm{OD}_{\text {Control }} \times 100 \%$.

\subsection{Microscale thermophoresis [43] assay}

To obtain cell lysates overexpressing constitutively active STAT3, H1299 cells transiently transfected with constitutively active STAT3c expression construct. $48 \mathrm{~h}$ after transfection, cells were harvested and lyzed in hypertonic buffer (20 mM HEPES. KOH, pH 7.9, $420 \mathrm{mM} \mathrm{KCl,} 1.5$ $\mathrm{mM} \mathrm{MgCl} 2,0.01 \mathrm{mM} \mathrm{NaP}_{2} \mathrm{O}_{7}, 1 \mathrm{mM} \mathrm{Na}_{3} \mathrm{VO}_{4}, 20 \mathrm{mM} \mathrm{NaF}, 0.2 \mathrm{mM}$ EDTA, $20 \%$ glycerol, 1 mM PMSF, $0.5 \mathrm{mM}$ DTT) as well as centrifuged at $13,000 \mathrm{~g}$ for $10 \mathrm{~min}$ at $4{ }^{\circ} \mathrm{C}$ after three freezethaw cycles. The supernatants were collected and the protein concentrations were quantified by Bicinchoninic Acid Protein Assay Kit (Dingguo Changsheng Biotechnology, Beijing, China). For MST assay, $200 \mu \mathrm{g}$ of cell lysates were mixed with $0.5 \mathrm{nM}$ of Cy5-labeled double-strand DNA probe (5'-AGCTTCATTTCCCGTAAATCCCTA-3') in binding buffer (50 mM HEPES, 
pH 7.9, $250 \mathrm{mM} \mathrm{KCl}, 0.1 \%$ tween-20, $0.25 \mu \mathrm{g} / \mu \mathrm{l}$ BSA, $1.25 \mathrm{mM}$ PMSF). For competitive MST assay, cell lysates were pretreated with unlabeled DNA probe, A26 or respective compounds for $10 \mathrm{~min}$ at room temperature before addition of Cy5-labeled probe. MST measurements were conducted in standard capillaries on a Monolith NT.115 system (Nano Temper, München, Germany), using $100 \%$ laser power and 20/40\% light-emitting diode power. Data analysis was performed using the software provided with the Monolith NT.115.

\subsection{Western blotting}

Western blotting analysis was used to determine the protein expression level as previously described [70, 71]. In brief, proteins in cell lysates were extracted in TNN buffer $(50 \mathrm{mM}$ Tris. $\mathrm{HCl}, \mathrm{pH}$ 7.4, $150 \mathrm{mM} \mathrm{NaCl}, 20 \mathrm{mM}$ EDTA, 0.5\% NP-40, $50 \mathrm{mM} \mathrm{NaF}, 1 \mathrm{mM} \mathrm{Na} \mathrm{VO}_{4}, 2$ mM PMSF and $1 \mathrm{mM}$ DTT) and quantified by Bicinchoninic Acid Protein Assay Kit (Dingguo Changsheng Biotechnology). Equal amount of proteins in cell lysates were resolved by sodium dodecyl sulfate-polyacrylamide gel electrophoresis and electroblotted onto polyvinylidene difluoride membranes (EMD Millipore, Billerica, MA, USA). After incubation with the primary antibody for $2 \mathrm{~h}$ at room temperature or overnight at $4^{\circ} \mathrm{C}$, the membrane was subsequently probed with peroxidase-conjugated secondary antibodies and visualized by using ChemiDoc $\mathrm{XRS}^{+}$imaging system (Bio-Rad, Hercules, CA, USA) with enhanced chemiluminescence (Dingguo Changsheng Biotechnology).

\subsection{Real-time reverse transcription polymerase chain reaction (PCR)}

Real-time qPCR was used to determine the mRNA expression levels as we previously described [70, 71]. Total RNA isolation was performed using E.Z.N.A. ${ }^{\text {TM }}$ Total RNA Kit I 
(Omega Bio-tek, Norcross, GA, USA) according to the manufacturer's instructions followed by cDNA synthesis using All-In-One RT MasterMix Kit (Applied Biological Materials, Richmond, BC, Canada). The resultant cDNA was subjected to 40 cycles of PCR amplification on Stratagene Mx3000 system (Agilent, Santa Clara, CA, USA) using EvaGreen qPCR MaxterMix (Applied Biological Materials) under the following cycling condition: $95^{\circ} \mathrm{C}$ for $10 \mathrm{~min}$ and 40 cycles of $95^{\circ} \mathrm{C}$ for $15 \mathrm{~s}$ and $60^{\circ} \mathrm{C}$ for $1 \mathrm{~min}$. The primers for the genes of interest were shown as follows:; cyclin D1: forward, 5'-CTTCCTCTCCAAAATGCCAG-3', reverse, 5'AGAGATGGAAGGGGGAAAGA-3'; GAPDH: forward, 5'AAGGACTCATGACCACAGTCCAT-3', reverse, 5'-CCATCACGCCACAGTTTCC-3'; gp130: forward, 5'-TCTGGGAGTGCTGTTCTGCTT-3', reverse, 5'-TGTGCCTTGGAGGAGTGTGA3'; JAK2: forward, 5'-TTTGGCAACAGACAAATGGA-3', reverse, 5'GCAGGAAGCTGATGCCTATC-3'; STAT3, forward, 5'-GGCCCCTCGTCATCAAGA-3', reverse, 5'-TTTGACCAGCAACCTGACTTTAGT-3'; survivin, forward: 5'TGCCTGGCAGCCCTTTC-3', reverse, 5'-CCTCCAAGAAGGGCCAGTTC-3'. GAPDH was used as the internal control. The relative mRNA levels were determined using $2^{-\Delta \Delta \mathrm{Ct}}$ method.

\subsection{Flow cytometry analysis of apoptosis}

To quantify apoptotic cells, flow cytometry analysis was performed by using Annexin V/ propidium iodide (PI) Apoptosis Detection Kit (Dojindo, Shanghai, China) according to the manufacturer's instructions as previously described [70, 71]. Cells Annexin V and PI were analyzed by BD Accuri ${ }^{\mathrm{TM}}$ C6 Flow Cytometer (BD Biosciences, San Jose, CA, USA).

\subsection{Statistical analysis}


Unless otherwise indicated, Data were expressed as mean \pm standard deviation of at least three independent experiments. Student's $t$ test was used to determine the significant difference between two groups. A $p$ value of $<0.05$ was considered statistically significant.

\section{Acknowledgements}

This work was supported by the National Natural Science Foundation of China (Grant No. 81503091, 21572010 and 21772005), PUMC Youth Fund and the Fundamental Research Funds for the Central Universities (Grant No. 2017350002), General Financial Grant from the China Postdoctoral Science Foundation (Grant No. 2015M570906), and Postdoctoral Grant of Peking University-Tsinghua University Center for Life Science.

\section{Declarations of Interest}

None

\section{Authors' Contribution}

WH, ZML and JRC designed the study. WH and YL performed all the experiments. JW assisted in biological assays. WH, YL, JTZ, ZML and JRC analyzed the data. XY, HWJ and LRZ participated in interpretation of results. WH and YL drafted the manuscript. JTZ, ZML and JRC revised the manuscript. All authors read and approved the manuscript.

\section{References}

[1] G.R. Stark, J.E. Darnell, Jr., The JAK-STAT pathway at twenty, Immunity, 36 (2012) 503-514.

[2] T. Bowman, R. Garcia, J. Turkson, R. Jove, STATs in oncogenesis, Oncogene, 19 (2000) 2474-2488.

[3] J. Bromberg, J.E. Darnell, Jr., The role of STATs in transcriptional control and their impact on cellular function, Oncogene, 19 (2000) 2468-2473. 
[4] T. Hirano, K. Ishihara, M. Hibi, Roles of STAT3 in mediating the cell growth, differentiation and survival signals relayed through the IL-6 family of cytokine receptors, Oncogene, 19 (2000) 2548-2556.

[5] D.E. Levy, J.E. Darnell, Jr., Stats: transcriptional control and biological impact, Nature reviews. Molecular cell biology, 3 (2002) 651-662.

[6] S. Ghoshal, B.C. Fuchs, K.K. Tanabe, STAT3 is a key transcriptional regulator of cancer stem cell marker CD133 in HCC, Hepatobiliary surgery and nutrition, 5 (2016) 201-203.

[7] C. Zugowski, F. Lieder, A. Muller, J. Gasch, F.M. Corvinus, R. Moriggl, K. Friedrich, STAT3 controls matrix metalloproteinase-1 expression in colon carcinoma cells by both direct and AP-1-mediated interaction with the MMP-1 promoter, Biological chemistry, 392 (2011) 449-459.

[8] X. Zhang, P. Yin, D. Di, G. Luo, L. Zheng, J. Wei, J. Zhang, Y. Shi, J. Zhang, N. Xu, IL-6 regulates MMP-10 expression via JAK2/STAT3 signaling pathway in a human lung adenocarcinoma cell line, Anticancer research, 29 (2009) 4497-4501.

[9] G. Yuan, L. Qian, M. Shi, F. Lu, D. Li, M. Hu, M. Yu, B. Shen, N. Guo, HER2-dependent MMP-7 expression is mediated by activated STAT3, Cellular signalling, 20 (2008) 1284-1291.

[10] G.Z. Cheng, W.Z. Zhang, M. Sun, Q. Wang, D. Coppola, M. Mansour, L.M. Xu, C. Costanzo, J.Q. Cheng, L.H. Wang, Twist is transcriptionally induced by activation of STAT3 and mediates STAT3 oncogenic function, The Journal of biological chemistry, 283 (2008) 14665-14673.

[11] K. Leslie, C. Lang, G. Devgan, J. Azare, M. Berishaj, W. Gerald, Y.B. Kim, K. Paz, J.E. Darnell, C. Albanese, T. Sakamaki, R. Pestell, J. Bromberg, Cyclin D1 is transcriptionally regulated by and required for transformation by activated signal transducer and activator of transcription 3, Cancer research, 66 (2006) 2544-2552.

[12] M. Itoh, T. Murata, T. Suzuki, M. Shindoh, K. Nakajima, K. Imai, K. Yoshida, Requirement of STAT3 activation for maximal collagenase-1 (MMP-1) induction by epidermal growth factor and malignant characteristics in T24 bladder cancer cells, Oncogene, 25 (2006) 1195-1204.

[13] T. Gritsko, A. Williams, J. Turkson, S. Kaneko, T. Bowman, M. Huang, S. Nam, I. Eweis, N. Diaz, D. Sullivan, S. Yoder, S. Enkemann, S. Eschrich, J.H. Lee, C.A. Beam, J. Cheng, S. Minton, C.A. Muro-Cacho, R. Jove, Persistent activation of stat 3 signaling induces survivin gene expression and confers resistance to apoptosis in human breast cancer cells, Clin Cancer Res, 12 (2006) 11-19.

[14] T.X. Xie, D. Wei, M. Liu, A.C. Gao, F. Ali-Osman, R. Sawaya, S. Huang, Stat3 activation regulates the expression of matrix metalloproteinase-2 and tumor invasion and metastasis, Oncogene, 23 (2004) 3550-3560.

[15] T.N. Dechow, L. Pedranzini, A. Leitch, K. Leslie, W.L. Gerald, I. Linkov, J.F. Bromberg, Requirement of matrix metalloproteinase- 9 for the transformation of human mammary epithelial cells by Stat3-C, Proceedings of the National Academy of Sciences of the United States of America, 101 (2004) 1060210607.

[16] D. Wei, X. Le, L. Zheng, L. Wang, J.A. Frey, A.C. Gao, Z. Peng, S. Huang, H.Q. Xiong, J.L. Abbruzzese, K. Xie, Stat3 activation regulates the expression of vascular endothelial growth factor and human pancreatic cancer angiogenesis and metastasis, Oncogene, 22 (2003) 319-329.

[17] G. Niu, K.L. Wright, M. Huang, L. Song, E. Haura, J. Turkson, S. Zhang, T. Wang, D. Sinibaldi, D. Coppola, R. Heller, L.M. Ellis, J. Karras, J. Bromberg, D. Pardoll, R. Jove, H. Yu, Constitutive Stat3 activity up-regulates VEGF expression and tumor angiogenesis, Oncogene, 21 (2002) 2000-2008.

[18] N. Kiuchi, K. Nakajima, M. Ichiba, T. Fukada, M. Narimatsu, K. Mizuno, M. Hibi, T. Hirano, STAT3 is required for the gp130-mediated full activation of the c-myc gene, The Journal of experimental medicine, 189 (1999) 63-73.

[19] M. Tong, J. Wang, N. Jiang, H. Pan, D. Li, Correlation between p-STAT3 overexpression and prognosis in lung cancer: A systematic review and meta-analysis, PloS one, 12 (2017) e0182282.

[20] J. Permuth-Wey, W.J. Fulp, B.M. Reid, Z. Chen, C. Georgeades, J.Q. Cheng, A. Magliocco, D.T. Chen, J.M. Lancaster, STAT3 polymorphisms may predict an unfavorable response to first-line platinum-based 
therapy for women with advanced serous epithelial ovarian cancer, International journal of cancer. Journal international du cancer, 138 (2016) 612-619.

[21] S. He, G. Liao, Y. Liu, L. Huang, M. Kang, L. Chen, Overexpression of STAT3/pSTAT3 was associated with poor prognosis in gastric cancer: a meta-analysis, Int J Clin Exp Med, 8 (2015) 20014-20023.

[22] M. Eto, T. Kamba, H. Miyake, M. Fujisawa, T. Kamai, H. Uemura, T. Tsukamoto, H. Azuma, A. Matsubara, K. Nishimura, T. Nakamura, O. Ogawa, S. Naito, S.-S.G.f.K.C. Japan Immunotherapy, STAT3 polymorphism can predict the response to interferon-alpha therapy in patients with metastatic renal cell carcinoma, European urology, 63 (2013) 745-752.

[23] E. Dobi, F. Monnien, S. Kim, A. Ivanaj, T. N'Guyen, M. Demarchi, O. Adotevi, A. Thierry-Vuillemin, M. Jary, B. Kantelip, X. Pivot, Y. Godet, S.V. Degano, C. Borg, Impact of STAT3 phosphorylation on the clinical effectiveness of anti-EGFR-based therapy in patients with metastatic colorectal cancer, Clinical colorectal cancer, 12 (2013) 28-36.

[24] C.H. Choi, S.Y. Song, H. Kang, Y.Y. Lee, C.J. Kim, J.W. Lee, T.J. Kim, B.G. Kim, J.H. Lee, D.S. Bae, Prognostic significance of p-STAT3 in patients with bulky cervical carcinoma undergoing neoadjuvant chemotherapy, The journal of obstetrics and gynaecology research, 36 (2010) 304-310.

[25] N. Diaz, S. Minton, C. Cox, T. Bowman, T. Gritsko, R. Garcia, I. Eweis, M. Wloch, S. Livingston, E. Seijo, A. Cantor, J.H. Lee, C.A. Beam, D. Sullivan, R. Jove, C.A. Muro-Cacho, Activation of stat3 in primary tumors from high-risk breast cancer patients is associated with elevated levels of activated SRC and survivin expression, Clinical cancer research : an official journal of the American Association for Cancer Research, 12 (2006) 20-28.

[26] T. Yoshikawa, M. Miyamoto, T. Aoyama, H. Soyama, T. Goto, J. Hirata, A. Suzuki, I. Nagaoka, H. Tsuda, K. Furuya, M. Takano, JAK2/STAT3 pathway as a therapeutic target in ovarian cancers, Oncol Lett, 15 (2018) 5772-5780.

[27] M. Spitzner, R. Ebner, H.A. Wolff, B.M. Ghadimi, J. Wienands, M. Grade, STAT3: A Novel Molecular Mediator of Resistance to Chemoradiotherapy, Cancers (Basel), 6 (2014) 1986-2011.

[28] A. Tchirkov, C. Rolhion, S. Bertrand, J.F. Dore, J.J. Dubost, P. Verrelle, IL-6 gene amplification and expression in human glioblastomas, Br J Cancer, 85 (2001) 518-522.

[29] M. Colomiere, A.C. Ward, C. Riley, M.K. Trenerry, D. Cameron-Smith, J. Findlay, L. Ackland, N. Ahmed, Cross talk of signals between EGFR and IL-6R through JAK2/STAT3 mediate epithelialmesenchymal transition in ovarian carcinomas, Br J Cancer, 100 (2009) 134-144.

[30] C.H. Squarize, R.M. Castilho, V. Sriuranpong, D.S. Pinto, Jr., J.S. Gutkind, Molecular cross-talk between the NFkappaB and STAT3 signaling pathways in head and neck squamous cell carcinoma, Neoplasia, 8 (2006) 733-746.

[31] M.A. Fragoso, A.K. Patel, R.E. Nakamura, H. Yi, K. Surapaneni, A.S. Hackam, The Wnt/beta-catenin pathway cross-talks with STAT3 signaling to regulate survival of retinal pigment epithelium cells, PLoS One, 7 (2012) e46892.

[32] S. Stella, E. Tirro, E. Conte, F. Stagno, F. Di Raimondo, L. Manzella, P. Vigneri, Suppression of survivin induced by a BCR-ABL/JAK2/STAT3 pathway sensitizes imatinib-resistant CML cells to different cytotoxic drugs, Mol Cancer Ther, 12 (2013) 1085-1098.

[33] W.J. Sheng, H. Jiang, D.L. Wu, J.H. Zheng, Early responses of the STAT3 pathway to platinum drugs are associated with cisplatin resistance in epithelial ovarian cancer, Braz J Med Biol Res, 46 (2013) 650658.

[34] H. Yan, B.Y. Guo, S. Zhang, Cancer-associated fibroblasts attenuate Cisplatin-induced apoptosis in ovarian cancer cells by promoting STAT3 signaling, Biochem Biophys Res Commun, 470 (2016) 947-954.

[35] B. Zhou, C. Sun, N. Li, W. Shan, H. Lu, L. Guo, E. Guo, M. Xia, D. Weng, L. Meng, J. Hu, D. Ma, G. Chen, Cisplatin-induced CCL5 secretion from CAFs promotes cisplatin-resistance in ovarian cancer via regulation of the STAT3 and PI3K/Akt signaling pathways, Int J Oncol, 48 (2016) 2087-2097. 
[36] Y.J. Tang, Z.L. Sun, W.G. Wu, J. Xing, Y.F. He, D.M. Xin, P. Han, Inhibitor of signal transducer and activator of transcription 3 (STAT3) suppresses ovarian cancer growth, migration and invasion and enhances the effect of cisplatin in vitro, Genet Mol Res, 14 (2015) 2450-2460.

[37] T. Ji, D. Gong, Z. Han, X. Wei, Y. Yan, F. Ye, W. Ding, J. Wang, X. Xia, F. Li, W. Hu, Y. Lu, S. Wang, J. Zhou, D. Ma, Q. Gao, Abrogation of constitutive Stat3 activity circumvents cisplatin resistant ovarian cancer, Cancer Lett, 341 (2013) 231-239.

[38] P. Yue, J. Turkson, Targeting STAT3 in cancer: how successful are we?, Expert opinion on investigational drugs, 18 (2009) 45-56.

[39] J. Deng, F. Grande, N. Neamati, Small molecule inhibitors of Stat3 signaling pathway, Current cancer drug targets, 7 (2007) 91-107.

[40] B. Debnath, S. Xu, N. Neamati, Small molecule inhibitors of signal transducer and activator of transcription 3 (Stat3) protein, Journal of medicinal chemistry, 55 (2012) 6645-6668.

[41] V. Ramakrishnan, T. Kimlinger, J. Haug, M. Timm, L. Wellik, T. Halling, A. Pardanani, A. Tefferi, S.V. Rajkumar, S. Kumar, TG101209, a novel JAK2 inhibitor, has significant in vitro activity in multiple myeloma and displays preferential cytotoxicity for CD45+ myeloma cells, American journal of hematology, 85 (2010) 675-686.

[42] S. Kunigal, S.S. Lakka, P.K. Sodadasu, N. Estes, J.S. Rao, Stat3-siRNA induces Fas-mediated apoptosis in vitro and in vivo in breast cancer, International journal of oncology, 34 (2009) 1209-1220.

[43] M. Hedvat, D. Huszar, A. Herrmann, J.M. Gozgit, A. Schroeder, A. Sheehy, R. Buettner, D. Proia, C.M. Kowolik, H. Xin, B. Armstrong, G. Bebernitz, S. Weng, L. Wang, M. Ye, K. McEachern, H. Chen, D. Morosini, K. Bell, M. Alimzhanov, S. Ioannidis, P. McCoon, Z.A. Cao, H. Yu, R. Jove, M. Zinda, The JAK2 inhibitor AZD1480 potently blocks Stat3 signaling and oncogenesis in solid tumors, Cancer Cell, 16 (2009) 487-497.

[44] A. Ferrajoli, S. Faderl, Q. Van, P. Koch, D. Harris, Z. Liu, I. Hazan-Halevy, Y. Wang, H.M. Kantarjian, W. Priebe, Z. Estrov, WP1066 disrupts Janus kinase-2 and induces caspase-dependent apoptosis in acute myelogenous leukemia cells, Cancer research, 67 (2007) 11291-11299.

[45] C. Huang, J. Cao, K.J. Huang, F. Zhang, T. Jiang, L. Zhu, Z.J. Qiu, Inhibition of STAT3 activity with AG490 decreases the invasion of human pancreatic cancer cells in vitro, Cancer science, 97 (2006) 14171423.

[46] W. Hao, Y. Hu, C. Niu, X. Huang, C.P. Chang, J. Gibbons, J. Xu, Discovery of the catechol structural moiety as a Stat3 SH2 domain inhibitor by virtual screening, Bioorganic \& medicinal chemistry letters, 18 (2008) 4988-4992.

[47] K. Siddiquee, S. Zhang, W.C. Guida, M.A. Blaskovich, B. Greedy, H.R. Lawrence, M.L. Yip, R. Jove, M.M. McLaughlin, N.J. Lawrence, S.M. Sebti, J. Turkson, Selective chemical probe inhibitor of Stat3, identified through structure-based virtual screening, induces antitumor activity, Proceedings of the National Academy of Sciences of the United States of America, 104 (2007) 7391-7396.

[48] J. Schust, B. Sperl, A. Hollis, T.U. Mayer, T. Berg, Stattic: a small-molecule inhibitor of STAT3 activation and dimerization, Chemistry \& biology, 13 (2006) 1235-1242.

[49] H. Song, R. Wang, S. Wang, J. Lin, A low-molecular-weight compound discovered through virtual database screening inhibits Stat 3 function in breast cancer cells, Proceedings of the National Academy of Sciences of the United States of America, 102 (2005) 4700-4705.

[50] J. Turkson, J.S. Kim, S. Zhang, J. Yuan, M. Huang, M. Glenn, E. Haura, S. Sebti, A.D. Hamilton, R. Jove, Novel peptidomimetic inhibitors of signal transducer and activator of transcription 3 dimerization and biological activity, Molecular cancer therapeutics, 3 (2004) 261-269.

[51] Z. Ren, L.A. Cabell, T.S. Schaefer, J.S. McMurray, Identification of a high-affinity phosphopeptide inhibitor of Stat3, Bioorganic \& medicinal chemistry letters, 13 (2003) 633-636. 
[52] J. Turkson, D. Ryan, J.S. Kim, Y. Zhang, Z. Chen, E. Haura, A. Laudano, S. Sebti, A.D. Hamilton, R. Jove, Phosphotyrosyl peptides block Stat3-mediated DNA binding activity, gene regulation, and cell transformation, The Journal of biological chemistry, 276 (2001) 45443-45455.

[53] J. Yang, X. Liao, M.K. Agarwal, L. Barnes, P.E. Auron, G.R. Stark, Unphosphorylated STAT3 accumulates in response to IL-6 and activates transcription by binding to NFkappaB, Genes \& development, 21 (2007) 1396-1408.

[54] T. Pawson, SH2 and SH3 domains in signal transduction, Advances in cancer research, 64 (1994) 87110.

[55] G.B. Cohen, R. Ren, D. Baltimore, Modular binding domains in signal transduction proteins, Cell, 80 (1995) 237-248.

[56] M. Sen, S.M. Thomas, S. Kim, J.I. Yeh, R.L. Ferris, J.T. Johnson, U. Duvvuri, J. Lee, N. Sahu, S. Joyce, M.L. Freilino, H. Shi, C. Li, D. Ly, S. Rapireddy, J.P. Etter, P.K. Li, L. Wang, S. Chiosea, R.R. Seethala, W.E. Gooding, X. Chen, N. Kaminski, K. Pandit, D.E. Johnson, J.R. Grandis, First-in-human trial of a STAT3 decoy oligonucleotide in head and neck tumors: implications for cancer therapy, Cancer discovery, 2 (2012) 694-705.

[57] W. Huang, Z. Dong, F. Wang, H. Peng, J.Y. Liu, J.T. Zhang, A small molecule compound targeting STAT3 DNA-binding domain inhibits cancer cell proliferation, migration, and invasion, ACS Chem Biol, 9 (2014) 1188-1196.

[58] W. Huang, Z. Dong, Y. Chen, F. Wang, C.J. Wang, H. Peng, Y. He, G. Hangoc, K. Pollok, G. Sandusky, X.Y. Fu, H.E. Broxmeyer, Z.Y. Zhang, J.Y. Liu, J.T. Zhang, Small-molecule inhibitors targeting the DNAbinding domain of STAT3 suppress tumor growth, metastasis and STAT3 target gene expression in vivo, Oncogene, 35 (2016) 802.

[59] P.C. Hawkins, A.G. Skillman, A. Nicholls, Comparison of shape-matching and docking as virtual screening tools, Journal of medicinal chemistry, 50 (2007) 74-82.

[60] S.Y. Yang, Pharmacophore modeling and applications in drug discovery: challenges and recent advances, Drug Discov Today, 15 (2010) 444-450.

[61] Z. Han, J. Feng, Z. Hong, L. Chen, W. Li, S. Liao, X. Wang, T. Ji, S. Wang, D. Ma, G. Chen, Q. Gao, Silencing of the STAT3 signaling pathway reverses the inherent and induced chemoresistance of human ovarian cancer cells, Biochemical and biophysical research communications, 435 (2013) 188-194.

[62] D.W. Shen, L.M. Pouliot, M.D. Hall, M.M. Gottesman, Cisplatin resistance: a cellular self-defense mechanism resulting from multiple epigenetic and genetic changes, Pharmacol Rev, 64 (2012) 706-721.

[63] H. Zhu, H. Luo, W. Zhang, Z. Shen, X. Hu, X. Zhu, Molecular mechanisms of cisplatin resistance in cervical cancer, Drug Des Devel Ther, 10 (2016) 1885-1895.

[64] L. Galluzzi, L. Senovilla, I. Vitale, J. Michels, I. Martins, O. Kepp, M. Castedo, G. Kroemer, Molecular mechanisms of cisplatin resistance, Oncogene, 31 (2012) 1869-1883.

[65] E. Comsa, K.A. Nguyen, F. Loghin, A. Boumendjel, M. Peuchmaur, T. Andrieu, P. Falson, Ovarian cancer cells cisplatin sensitization agents selected by mass cytometry target $A B C C 2$ inhibition, Future Med Chem, 10 (2018) 1349-1360.

[66] Q. Liu, D. Zhu, B. Hao, Z. Zhang, Y. Tian, Luteolin promotes the sensitivity of cisplatin in ovarian cancer by decreasing PRPA1-medicated autophagy, Cell Mol Biol (Noisy-le-grand), 64 (2018) 17-22.

[67] H. Itamochi, M. Nishimura, N. Oumi, M. Kato, T. Oishi, M. Shimada, S. Sato, J. Naniwa, S. Sato, A. Kudoh, J. Kigawa, T. Harada, Checkpoint kinase inhibitor AZD7762 overcomes cisplatin resistance in clear cell carcinoma of the ovary, Int J Gynecol Cancer, 24 (2014) 61-69.

[68] T. Liu, H. Peng, M. Zhang, Y. Deng, Z. Wu, Cucurbitacin B, a small molecule inhibitor of the Stat3 signaling pathway, enhances the chemosensitivity of laryngeal squamous cell carcinoma cells to cisplatin, European journal of pharmacology, 641 (2010) 15-22.

[69] M.J. Axelrod, R.E. Mendez, A. Khalil, S.S. Leimgruber, E.R. Sharlow, B. Capaldo, M. Conaway, D.G. Gioeli, M.J. Weber, M.J. Jameson, Synergistic apoptosis in head and neck squamous cell carcinoma cells 
by co-inhibition of insulin-like growth factor-1 receptor signaling and compensatory signaling pathways, Head Neck, 37 (2015) 1722-1732.

[70] W. Huang, X. Yuan, T. Sun, S. Fan, J. Wang, Q. Zhou, W. Guo, F. Ran, Z. Ge, H. Yang, R. Li, J. Cui, Proteasome Inhibitor YSY01A Abrogates Constitutive STAT3 Signaling via Down-regulation of Gp130 and JAK2 in Human A549 Lung Cancer Cells, Front Pharmacol, 8 (2017) 476.

[71] W. Huang, Q. Zhou, X. Yuan, Z.M. Ge, F.X. Ran, H.Y. Yang, G.L. Qiang, R.T. Li, J.R. Cui, Proteasome Inhibitor YSY01A Enhances Cisplatin Cytotoxicity in Cisplatin-Resistant Human Ovarian Cancer Cells, J Cancer, 7 (2016) 1133-1141. 


\section{Highlights}

1. DNA-binging domain of STAT3 may not be 'undruggable' as previously thought

2. LC28 and five analogs were identified through the pharmacophore of known STAT3 inhibitors with 3D shape- and electrostatic-based drug design

3. Microscale thermophoresis assay shows that these compounds inhibits STAT3 binding to DNA with a Ki value of $0.74 \sim 8.87 \mu \mathrm{M}$.

4. LC28 and its analogs suppress survival of cisplatin-resistant ovarian cancer cells by inhibiting STAT3 signaling and inducing apoptosis. 